\title{
Prevalence and risk factors of overweight and obesity among individuals over 40 years old in Luzhou city
}

\author{
J. Zeng, Q. Wan, X. Bai, X.Z. Li, F. Liu, C. Li, X.Y. Liu and Y. Wang \\ Department of Endocrinology, the Affiliated Hospital of Luzhou Medical College, \\ Luzhou, China \\ Corresponding author: Q. Wan \\ E-mail: qinwancn@yeah.net
}

Genet. Mol. Res. 13 (4): 9262-9270 (2014)

Received June 3, 2013

Accepted September 12, 2013

Published May 16, 2014

DOI http://dx.doi.org/10.4238/2014.May.16.14

\begin{abstract}
In this study, a survey was conducted through questionnaire distribution and physical examinations were performed in 10,150 residents that were over 40 years old in Luzhou city. Respondents were selected by the multi-stage sampling method. The mean body mass index (BMI) of the sample population was $23.9 \pm 3.3 \mathrm{~kg} / \mathrm{m}^{2}$. Among men, BMI showed a negative relationship with increasing age $(\mathrm{P}<0.05)$, whereas among women, it showed a positive relationship $(\mathrm{P}<0.001)$. The rates of overweight and obesity increased with age and reached a peak between 60 to 70 years of age $(\mathrm{P}<0.001)$. The rates of overweight and obesity varied with different working conditions, training situations, educational levels, marital status, and other factors $(\mathrm{P}<0.05)$. Age, educational level, daily sitting time, and family history of diabetes were factors that influenced the prevalence of overweight and obesity through multivariate logistic regression analysis $(\mathrm{P}<0.05)$. The incidences of overweight and obesity among the middle-aged population were
\end{abstract}


found to be significantly high. Therefore, prevention and control measures should be adopted as soon as possible.

Key words: Body mass index; Middle-aged; Obesity; Overweight; Prevalence; Risk factors

\section{INTRODUCTION}

The latest data from the World Health Organization (WHO) show that approximately 15 million adults 20 years old and above are overweight, of which more than 200 million men and nearly 300 million women were obese, indicating that more than $10 \%$ of the world's adult population are obese (Obesity and Overweight [EB/OL], WHO). In low- and middle-income countries, overweight and obesity rates are significantly higher, especially in urban areas. The prevalence of overweight and obesity is also rising in China (Wu et al., 2005). In the past decade, obesity has become a substantial threat to health and a major public health challenge. Obesity increases the risks of coronary heart diseases, type 2 diabetes, cancer, high blood pressure, sleep apnea syndrome, biliary tract disease, osteoarthritis, and other diseases. In 2008, the medical cost related to obesity was estimated to have reached $\$ 14.7$ billion in the United States. Overweight and obesity have therefore resulted in heavy economic burdens in the country (Ma et al., 2002; Finkelstein et al., 2009; Centers for Disease Control and Prevention (CDC), 2010). Domestic and international studies have shown that overweight and obesity rates increase with increasing age (WHO, 2000; Wu et al., 2005). The process of aging in the population of China is accelerating; aging has become more evident and health problems have become increasingly pronounced in the elderly population (Hu and Peng, 2011). Age, overweight, and obesity are all risk factors for cardiovascular and cerebrovascular diseases, diabetes, cancer, and other diseases (Dong et al., 2009). There are few studies on the prevalence of overweight and obesity in China and other countries, particularly among the middle-aged population. The current study was designed to determine overweight and obesity epidemic distribution rules and risk factors in the Luzhou region through a survey on overweight and obesity status among members of the population who are over 40 years old. The results of this study should provide a foundation for the control of overweight and obesity in the middle-aged population.

\section{MATERIAL AND METHODS}

\section{Subjects}

The subjects of this study were residents of Luzhou city from May 2011 to November 2011. Six communities were randomly selected in the city by the multi-stage sampling method. Streets were randomly selected from each community, and then subjects were randomly selected from each street. The subjects, who were all over 40 years old, voluntarily participated. They completed the questionnaire and underwent a physical examination. Gender was not limited, and both men and women were included in this study. Subjects with mobility and communication barriers were eliminated. This study was conducted in accordance with the declaration of Helsinki, and with approval from the Ethics Committee of the Affiliated Hospital of Luzhou Medical College. Written informed consent was obtained from all participants. 


\section{Data collection}

A standardized questionnaire survey was performed to collect general information (gender, age, community, etc.), lifestyle (eating habits, exercise activities, etc.), work situation, medical history, obstetrical history, menstrual history, and personal history. All investigators received unified training. All subjects underwent routine physical examinations, which included determinations of height, weight, and resting blood pressure. Height was exacted to $0.1 \mathrm{~cm}$ and weight was exacted to $0.1 \mathrm{~kg}$.

\section{Defined indicators}

The standards for overweight and obesity were based on "The Prevention Guide for Overweight and Obesity in Chinese Adults": the body mass index (BMI) for overweight individuals is between $24 \mathrm{~kg} / \mathrm{m}^{2}$ and $27.9 \mathrm{~kg} / \mathrm{m}^{2}$ and the BMI for obesity is more than $28 \mathrm{~kg} /$ $\mathrm{m}^{2}$ (Chen et al., 2003). Overweight and obesity can be divided into three groups based on the alcohol consumption classification criteria of the 2005 US Dietary Guidelines: 1) moderate alcohol consumption refers to $\leq 2$ drinks/day for men and $\leq 1$ drink/day for women, 2) heavy drinking refers to $>2$ drinks/day for men and $>1$ drink/day for women ( 1 drink $=14 \mathrm{~g}$ ethanol, equivalent to $360 \mathrm{~mL}$ beer, $180 \mathrm{~mL} / 140 \mathrm{~g}$ wine, or $45 \mathrm{~mL} / 42 \mathrm{~g}$ ethanol drinks of 90 standard degrees), and 3) no drinking. This standard is based on the amount of alcohol beverages consumed in any given day, and not the daily average volume (US Department of Agriculture and Health and Human Services, 2005). Sedentary behavior refers to actions in which energy consumption does not increase above the resting level (such as sleeping, sitting, lying down, watching TV, and other forms of screen behavior) (Pate et al., 2008). According to the WHO diet standard, the daily intake of fruits and vegetables associated with overweight/obesity is less than $400 \mathrm{~g}$ (WHO, 2003).

\section{Statistical analysis}

This study was designed to employ Epidata data entry and to perform statistical analysis using the SPSS Statistics 17.0 software package. Continuous variables between groups were compared through the Student $t$-test. Rates between groups were compared with the $\chi^{2}$ test. Trends were also analyzed with the $\chi^{2}$ test. For single-factor $\chi^{2}$ tests and multivariate logistic regression analysis, $\mathrm{P}<0.05$ indicated that the difference was statistically significant.

\section{RESULTS}

\section{General information}

A total of 10,150 individuals above 40 years old participated in this investigation, from which 10,007 copies of valid questionnaires were collected. The respondents were composed of 3442 men, accounting for $34.40 \%$ of the sample population, and 6565 women, accounting for $65.60 \%$ of the population. The average age was $58.7 \pm 10.1$ years. A normality test was performed on the BMI of middle-aged individuals over the age of 40 . We found that the resulting data followed a normal distribution $(\mathrm{Z}=1.344, \mathrm{P}=0.054)$. The mean $\mathrm{BMI}$ was 
$23.9 \pm 3.3 \mathrm{~kg} / \mathrm{m}^{2}$; the mean male BMI was $24.0 \pm 3.2 \mathrm{~kg} / \mathrm{m}^{2}$ and the mean female BMI was $23.9 \pm 3.4 \mathrm{~kg} / \mathrm{m}^{2}$ (Table 1). No statistically significant difference was found in the BMIs of men and women $(t=-0.827, \mathrm{P}=0.408)$. Male BMI decreased with increasing age, and the difference was statistically significant $\left(r_{s}=-0.039, P=0.025\right)$. By contrast, female BMI increased with increasing age, and the difference was also statistically significant $\left(r_{s}=0.126, P<0.001\right)$.

\begin{tabular}{|c|c|c|c|c|c|c|}
\hline \multirow[t]{2}{*}{ Age group (years) } & \multicolumn{2}{|c|}{ Male } & \multicolumn{2}{|c|}{ Female } & \multicolumn{2}{|c|}{ Total } \\
\hline & $\mathrm{N}$ & Means \pm SD & $\mathrm{N}$ & Means \pm SD & $\mathrm{N}$ & Means \pm SD \\
\hline $40 \sim$ & 592 & $24.2 \pm 3.3$ & 1582 & $23.3 \pm 3.1$ & 2174 & $23.5 \pm 3.2$ \\
\hline $50 \sim$ & 949 & $23.8 \pm 3.1$ & 2356 & $23.9 \pm 3.3$ & 3305 & $23.9 \pm 3.3$ \\
\hline $60 \sim$ & 1221 & $24.1 \pm 3.1$ & 1737 & $24.4 \pm 3.5$ & 2958 & $24.3 \pm 3.3$ \\
\hline $70 \sim$ & 579 & $23.7 \pm 3.2$ & 777 & $24.2 \pm 3.5$ & 1356 & $24.0 \pm 3.4$ \\
\hline $80 \sim$ & 101 & $23.0 \pm 3.5$ & 113 & $23.3 \pm 3.6$ & 214 & $23.2 \pm 3.5$ \\
\hline Total & 3442 & $24.0 \pm 3.2$ & 6565 & $23.9 \pm 3.4$ & 10007 & $23.9 \pm 3.3$ \\
\hline
\end{tabular}

\section{Distribution of overweight rates across different ages and genders}

The overweight rate for individuals over 40 years old was $36.19 \%$, of which males accounted for $38.41 \%$ and females accounted for $35.03 \%$. The difference between men and women was statistically significant $\left(\chi^{2}=10.362, \mathrm{P}=0.001\right)$. The difference in overweight rate between men and women in the 40 years and above age group was statistically significant $\left(\chi^{2}\right.$ $=9.752, \mathrm{P}<0.02)$; the differences among other age groups were not statistically significant (Table 2$)$. The overweight rate differed significantly among age groups $\left(\chi^{2}=36.947, \mathrm{P}<\right.$ $0.001)$. The overweight rate rose gradually with increasing age, and reached a peak among respondents in their $60 \mathrm{~s}\left(\chi^{2}=8.261, \mathrm{P}<0.01\right)$. The analysis by gender indicated that overweight rates varied significantly in females of different age groups $\left(\chi^{2}=24.173, \mathrm{P}<0.001\right)$, which tended to increase with age and reached a peak for women in their 60s. Overweight rates for males also varied significantly across age groups $\left(\chi^{2}=17.188, \mathrm{P}=0.002\right)$; however, the overweight rate had no upward trend with age among males (Table 2 ).

\begin{tabular}{|c|c|c|c|c|c|c|c|c|c|c|c|}
\hline \multirow{2}{*}{$\begin{array}{l}\text { Age group } \\
\text { (years) }\end{array}$} & \multicolumn{3}{|c|}{ Male } & \multicolumn{3}{|c|}{ Female } & \multicolumn{3}{|c|}{ Total } & \multirow[t]{2}{*}{$\chi^{2}$} & \multirow[t]{2}{*}{$\mathrm{P}$} \\
\hline & No. & $\begin{array}{c}\text { No. of } \\
\text { overweight }\end{array}$ & $\begin{array}{l}\text { Overweight } \\
\text { rate }(\%)\end{array}$ & No. & $\begin{array}{c}\text { No. of } \\
\text { overweight }\end{array}$ & $\begin{array}{l}\text { Overweight } \\
\text { rate }(\%)\end{array}$ & No. & $\begin{array}{c}\text { No. of } \\
\text { overweight }\end{array}$ & $\begin{array}{l}\text { Overweight } \\
\text { rate }(\%)\end{array}$ & & \\
\hline $40 \sim$ & 592 & 226 & 38.18 & 1582 & 492 & 31.10 & 2174 & 718 & 33.03 & 9.751 & 0.002 \\
\hline $50 \sim$ & 949 & 338 & 35.62 & 2356 & 821 & 34.85 & 3305 & 1159 & 35.07 & 0.176 & 0.675 \\
\hline $60 \sim$ & 1221 & 508 & 41.61 & 1737 & 679 & 39.09 & 2958 & 1187 & 40.13 & 1.752 & 0.186 \\
\hline $70 \sim$ & 579 & 226 & 39.03 & 777 & 273 & 35.14 & 1356 & 499 & 36.80 & 2.167 & 0.141 \\
\hline $80 \sim$ & 101 & 24 & 23.76 & 113 & 35 & 30.97 & 214 & 59 & 27.57 & 1.389 & 0.239 \\
\hline Total & 3442 & 1322 & 38.41 & 6565 & 2300 & 35.03 & 10007 & 3622 & 36.19 & 10.362 & 0.001 \\
\hline$\chi^{2}$ trend & \multicolumn{3}{|c|}{0.005} & \multicolumn{3}{|c|}{9.373} & \multicolumn{3}{|c|}{8.261} & & \\
\hline $\mathrm{P}$ value & \multicolumn{3}{|c|}{0.946} & \multicolumn{3}{|c|}{0.002} & \multicolumn{3}{|c|}{0.004} & & \\
\hline
\end{tabular}

\section{Distribution of obesity rates across different ages and genders}

The obesity rate for individuals over 40 years old was $11.32 \%$, of which males accounted for $10.89 \%$ and females accounted for $11.55 \%$. No significant difference was found 
between males and females. The obesity rate of males in their 40 s was significantly higher than that of females $\left(\chi^{2}=24.920, \mathrm{P}<0.001\right)$. The obesity rate of females in their $60 \mathrm{~s}$ and $70 \mathrm{~s}$ was significantly higher than that of males $(\mathrm{P}<0.001)$ (Table 3$)$. The incidences of obesity differed significantly across age groups $\left(\chi^{2}=29.955, \mathrm{P}<0.01\right)$. Overall, the obesity rate showed an upward trend with age and reached a peak in the 60s $\left(\chi^{2}=8.261, \mathrm{P}<0.01\right)$. The obesity rate of females significantly increased with age, whereas the obesity rate of males significantly decreased with age (Table 3 ).

\begin{tabular}{|c|c|c|c|c|c|c|c|c|c|c|c|}
\hline \multirow{2}{*}{$\begin{array}{l}\text { Age group } \\
\text { (years) }\end{array}$} & \multicolumn{3}{|c|}{ Male } & \multicolumn{3}{|c|}{ Female } & \multicolumn{3}{|c|}{ Total } & \multirow[t]{2}{*}{$\chi^{2}$} & \multirow[t]{2}{*}{$\mathrm{P}$} \\
\hline & No. & $\begin{array}{l}\text { No. of } \\
\text { obesity }\end{array}$ & $\begin{array}{l}\text { Obesity } \\
\text { rate }(\%)\end{array}$ & No. & $\begin{array}{l}\text { No. of } \\
\text { obesity }\end{array}$ & $\begin{array}{l}\text { Obesity } \\
\text { rate }(\%)\end{array}$ & No. & $\begin{array}{l}\text { No. of } \\
\text { obesity }\end{array}$ & $\begin{array}{l}\text { Obesity } \\
\text { rate }(\%)\end{array}$ & & \\
\hline $40 \sim$ & 592 & 81 & 13.68 & 1582 & 109 & 6.89 & 2174 & 190 & 8.74 & 24.920 & $<0.001$ \\
\hline $50 \sim$ & 949 & 101 & 10.64 & 2356 & 256 & 10.87 & 3305 & 357 & 10.80 & 0.035 & 0.852 \\
\hline $60 \sim$ & 1221 & 133 & 10.89 & 1737 & 262 & 15.08 & 2958 & 395 & 13.35 & 10.371 & 0.001 \\
\hline $70 \sim$ & 579 & 51 & 8.81 & 777 & 117 & 15.06 & 1356 & 168 & 12.39 & 11.938 & $<0.001$ \\
\hline $80 \sim$ & 101 & 9 & 8.91 & 113 & 14 & 12.39 & 214 & 23 & 10.75 & 0.673 & 0.412 \\
\hline Total & 3442 & 375 & 10.89 & 6565 & 758 & 11.55 & 10007 & 1133 & 11.32 & 0.935 & 0.334 \\
\hline$\chi^{2}$ trend & \multicolumn{3}{|c|}{5.975} & & \multicolumn{2}{|c|}{53.330} & \multicolumn{3}{|c|}{18.741} & & \\
\hline
\end{tabular}

\section{Distribution of overweight and obesity rates in different single-factor populations}

In this study, the following 11 factors were set as independent variables: gender, educational level, marital status, work, exercise (various forms of movement such as tai chi, dancing, aerobics, yoga, running, etc.), alcohol consumption, daily vegetable intake, family history of diabetes, sedentary time, birthday, and menstrual situation. These factors were statistically evaluated with respect to overweight and obesity rates, as well as the prevalence of a BMI $\geq$ $24 \mathrm{~kg} / \mathrm{m}^{2}$. The $\chi^{2}$ test revealed that overweight and obesity rates of male subjects who lacked exercise and who had stopped working were significantly higher than those of female subjects who exercised and who had a job. Among women, overweight and obesity rates of postmenopausal women were significantly higher than those of menstrual females. Overweight and obesity rates varied significantly among respondents with different marital status. Overweight and obesity rates decreased significantly with increased education level (Table 4). However, other factors, such as family history of diabetes, daily sitting time, daily vegetable intake, alcohol consumption, birthday, etc., had no influence on overweight and obesity rates (Table 4).

\section{Overweight and obesity risk factors}

Gender, age, educational level, marital status, work, exercise activities, alcohol consumption, daily vegetable intake, family history of diabetes, daily sitting time, birthday, and 11 other factors used as independent variables, were included in the non-conditional logistic regression model. Using a gradual forward method of analysis, age, educational level, daily sitting time, and family history of diabetes were determined to be significant factors influencing overweight and obesity. The difference was statistically significant among different groups (Table 5). The tendency for overweight and obesity increased with age and decreased with higher educational level. The risk of overweight and obesity was 1.144 times greater among 
people whose daily sitting time was more than $5 \mathrm{~h}$ compared with those whose daily sitting time was less than $5 \mathrm{~h}$. The risk was 1.161 times greater among people with a family history of diabetes than those with no family history of diabetes (Table 5). The effects of gender, exercise, alcohol consumption, daily vegetable intake, and birth month on overweight and obesity prevalence were not statistically significant (Table 5).

\begin{tabular}{|c|c|c|c|c|c|}
\hline Variants & No. & No. of overweight and obesity & Overweight and obesity rate (\%) & $\chi^{2}$ trend & $\mathrm{P}$ \\
\hline \multicolumn{6}{|l|}{ Gender } \\
\hline Male & 3359 & 1653 & 49.21 & \multirow[t]{2}{*}{6.167} & \multirow[t]{2}{*}{0.013} \\
\hline Female & 6565 & 3058 & 46.58 & & \\
\hline \multicolumn{6}{|l|}{ Exercise } \\
\hline Yes & 2209 & 982 & 44.45 & \multirow[t]{2}{*}{10.364} & \multirow[t]{2}{*}{0.001} \\
\hline \multirow{2}{*}{\multicolumn{6}{|c|}{ Work }} \\
\hline & & & & & \\
\hline Yes & 2158 & 950 & 44.02 & \multirow[t]{2}{*}{13.192} & \multirow[t]{2}{*}{$<0.001$} \\
\hline No & 7767 & 3762 & 48.44 & & \\
\hline \multicolumn{6}{|l|}{ Degree of education } \\
\hline Illiteracy or semiliterate & 975 & 491 & 50.36 & \multirow[t]{3}{*}{36.478} & \multirow[t]{2}{*}{$<0.001$} \\
\hline Primary school & 2434 & 1271 & 52.21 & & \\
\hline Junior high school & 3502 & 1636 & 46.72 & & \multirow{3}{*}{0.011} \\
\hline High school/secondary & 2042 & 877 & 42.95 & \multirow[t]{2}{*}{9.014} & \\
\hline Specific college course or above & 822 & 360 & 43.80 & & \\
\hline \multicolumn{6}{|l|}{ Marital status } \\
\hline Married or cohabiting & 8706 & 4174 & 47.94 & & \\
\hline Divorced/separated/widowed & 1040 & 462 & 44.42 & & \\
\hline & 39 & 12 & 30.77 & & \\
\hline \multicolumn{6}{|l|}{ Menopause (female) } \\
\hline Yes & 4907 & 2389 & 48.69 & 35.602 & $<0.001$ \\
\hline No & 1339 & 529 & 39.51 & & \\
\hline
\end{tabular}

\begin{tabular}{|c|c|c|c|c|c|c|}
\hline Variants & B & SE & Wald & $\mathrm{P}$ & OR & $95 \% \mathrm{CI}$ \\
\hline $\begin{array}{l}\text { Age group } \\
40 \sim\end{array}$ & & & 55.011 & $<0.001$ & 1 & \\
\hline $\begin{array}{l}40 \sim \\
50 \sim\end{array}$ & 0.121 & 0.062 & 3.830 & 0.050 & 1.128 & $1.000-1.273$ \\
\hline $60 \sim$ & 0.393 & 0.065 & 37.088 & $<0.001$ & 1.482 & $1.306-1.682$ \\
\hline $70 \sim$ & 0.312 & 0.079 & 15.619 & $<0.001$ & 1.366 & $1.170-1.595$ \\
\hline $80 \sim$ & -0.275 & 0.163 & 2.846 & 0.092 & 0.760 & $0.552-1.045$ \\
\hline Degree of education & & & 34.150 & $<0.001$ & & \\
\hline Illiteracy or semiliterate & & & & & 1 & \\
\hline Primary school & -0.005 & 0.084 & 0.003 & 0.955 & 0.995 & $0.844-1.174$ \\
\hline Junior high school & -0.174 & 0.083 & 4.410 & 0.036 & 0.841 & $0.715-0.988$ \\
\hline High school/secondary & -0.349 & 0.089 & 15.501 & $<0.001$ & 0.705 & $0.593-0.839$ \\
\hline Specific college course or above & -0.319 & 0.109 & 8.591 & 0.003 & 0.727 & $0.587-0.900$ \\
\hline Sedentary time $<5 \mathrm{~h} /$ day & & & & & 1 & \\
\hline$\geq 5 \mathrm{~h} /$ day & 0.134 & 0.051 & 6.832 & 0.009 & 1.144 & $1.034-1.265$ \\
\hline Diabetes history & & & & & & \\
\hline No & & & & & 1 & \\
\hline Yes & 0.150 & 0.075 & 3.990 & 0.046 & 1.161 & $1.003-1.345$ \\
\hline
\end{tabular}

\section{DISCUSSION}

Overweight and obesity are common conditions worldwide. Overweight is already very widespread in the Chinese population. The ratio of obesity shows the same growth rate as the ratio of overweight, and the potential dangers of both conditions to health are becoming increasingly apparent (Wu et al., 2005; Obesity and Overweight [EB/OL], WHO). This study 
was concerned with the prevalent characteristics of overweight and obesity in middle-aged populations, thus revealing the regular pattern of overweight and obesity. The middle-aged respondents in this study were all Luzhou city residents, a factor that may have contributed to the limitations of this study. This study showed that the ratios of overweight and obesity in people above 40 years old were 36.19 and $11.32 \%$, respectively, which means that 4 of 10 people are overweight, and 1 of 10 people is obese. These results demonstrate the alarming situation of overweight and obesity in China. The ratio of overweight and obesity is 3.5:1, which means that the potential risk of the progression from overweight to obesity is worthy of concern. The rates of overweight and obesity in our study are significantly higher than those reported in the national epidemiological survey of residents in 2002 (Wu et al., 2005), indicating that special attention should be paid to the middle-aged population with regard to the prevention and control of overweight and obesity. According to the 2002 national overweight and obesity epidemiological investigation, the rates of overweight and obesity among people older than 40 years in Luzhou were slightly lower than those of the urban population, higher than those of the rural population, and higher than the total incidence of urban and rural areas $(\mathrm{Wu}$ et al., 2005). The aforementioned study showed that the overweight rate was higher among males than among females, but no significant difference was found in the rate of obesity. According to the most recent US obesity epidemiology research, female obesity rates have always been higher than those of males; however, male obesity rates are increasing significantly. The ratio of obesity has not differed significantly between males and females in recent years (Flegal et al., 2010). As such, we speculate that obesity in males still has room for growth, and should not be ignored. Our study indicates that the obesity rate is higher among females above 60 years old than among males of this age group, which is consistent with results of similar local and international studies. For people more than 40 years old, the obesity rate was higher among males than among females, which is similar to the results from the CDC. In Chongqing, overweight and obesity rates are higher among males than among females for people older than 45 years old, whereas the result is reversed for people younger than 45 years old; such findings are slightly different from the data in our study (Flegal et al., 2010; Zhang et al., 2010). The different incidences of overweight and obesity in different ages and genders result from race, educational level, economic level, social status, and physiological hormonal changes (Wang and Beydoun, 2007). Overweight and obesity rates were significantly higher in postmenopausal women than in premenopausal women, suggesting that female hormones are closely related to overweight and obesity. One study showed that the mouse brain estrogen receptor could regulate energy expenditure and fat distribution. Another study confirmed that estrogen binds to estrogen receptors and takes part in glucose transport, synthesis of fat oxidation, and the mitochondrial respiratory chain. Therefore, estrogen and its involvement in obesity and other diseases has become a research hotspot (Gao et al., 2007; Chen et al., 2009; Newbold et al., 2009).

Genetic and living environment factors also contribute to the development and progression of overweight and obesity. This study showed that the risk of overweight and obesity increased in individuals with a family history of diabetes. Although the mechanism is not clear, a family history of diabetes is an easy characteristic to identify, thus taking positive interventions to prevent the development of overweight and obesity among this population would be undoubtedly beneficial. The risk of obesity was shown to increase by $23 \%$ for each additional $2 \mathrm{~h}$ of watching TV or sitting. Sedentary behavior, especially watching TV, greatly 
increases the risk of obesity (Hu et al., 2003; Suter, 2005). The present study showed that a sitting time of $\geq 5 \mathrm{~h}$ per day is one of the risk factors of overweight and obesity, which is consistent with foreign research conclusions. Reducing sitting time can prevent weight gain. This study also showed that good habits are beneficial for maintaining normal body weight, and that various forms of exercise, such as tai chi, dancing, aerobics, yoga, and running, are beneficial for middle-aged people. This investigation also suggests that alcohol consumption is not related to overweight and obesity among middle-aged people. The association between alcohol consumption and weight is controversial, and results from epidemiological research on alcohol consumption and weight also vary. However, a study from the US confirmed that moderate alcohol consumption was associated with overweight and obesity based on characteristics of energy metabolism (Hu et al., 2003). Variations in conclusions may result from different references for drinking standards, frequencies, and groups.

Luzhou is one of the medium-sized cities in western China, in which overweight and obesity are highly prevalent among middle-aged people. The overweight population is large, and the prevalence of obesity may increase further. Overweight and obesity are serious problems among the middle-aged population. In particular, the incidence of overweight and obesity is imminent among people with a family history of diabetes, middle-aged men, and menopausal women. Health education programs regarding overweight and obesity risk behaviors and lifestyles should be strengthened, thus prompting the promotion of a reasonable diet, exercise, and other healthy behaviors and lifestyles for the prevention and control of overweight and obesity among the middle-aged population.

\title{
ACKNOWLEDGMENTS
}

\author{
Research supported by the Chinese Society of Endocrinology (\#12020160276).
}

\section{REFERENCES}

Centers for Disease Control and Prevention (CDC) (2010). Vital signs: State-specific obesity prevalence among adults United States, 2009. MMWR 59: 951-955.

Chen CM, Kong LZ, Wen ZM, Zhou BF, et al. (2003). Guidelines on Prevention and Treatment of Overweight and Obesity. China Ministry of Health, Disease Control Division, Beijing, 1-50.

Chen JQ, Brown TR and Russo J (2009). Regulation of energy metabolism pathways by estrogens and estrogenic chemicals and potential implications in obesity associated with increased exposure to endocrine disruptors. Biochim. Biophys. Acta 1793: 1128-1143.

Dong BR, Wu HM and Ding QF (2009). Geriatrics [W]// Geriatrics Pandect. Sichuan University Press, Chengdu, 2-11.

Finkelstein EA, Trogdon JG, Cohen JW and Dietz W (2009). Annual medical spending attributable to obesity: payer-and service-specific estimates. Health Aff. 28: w822-w831.

Flegal KM, Carroll MD, Ogden CL and Curtin LR (2010). Prevalence and trends in obesity among US adults, 1999-2008. JAMA 303: 235-241.

Gao Q, Mezei G, Nie Y, Rao Y, et al. (2007). Anorectic estrogen mimics leptin's effect on the rewiring of melanocortin cells and Stat3 signaling in obese animals. Nat. Med. 13: 89-94.

Hu FB, Li TY, Colditz GA, Willett WC, et al. (2003). Television watching and other sedentary behaviors in relation to risk of obesity and type 2 diabetes mellitus in women. JAMA 289: 1785-1791.

$\mathrm{Hu} Z$ and Peng XZ (2011). China's population aging from the perspective of public policy. Social Sci. China 32: 106-124.

Ma WJ, Xu YJ, Li JS, Xu HF, et al. (2002). A review on the advancement of epidemiology on overweight and obesity. Foreign Med. Sci. 19: 316-320.

Newbold RR, Padilla-Banks E and Jefferson WN (2009). Environmental estrogens and obesity. Mol. Cell Endocrinol. 304: 84-89. 
Obesity and Overweight [EB/OL]. WHO. Available at [http://www.who.int/mediacentre/factsheets/fs311/en/]. Accessed March 11, 2012.

Pate RR, O'Neill JR and Lobelo F (2008). The evolving definition of "sedentary". Exerc. Sport Sci Rev. 36: 173-178.

Suter PM (2005). Is alcohol consumption a risk factor for weight gain and obesity? Crit Rev. Clin. Lab Sci 42: 197-227.

US Department of Agriculture and Health and Human Services (2005). Alcoholic beverages [W]// Dietary Guidelines for Americans. US Government Printing Office, Washington, DC, 43-46.

Wang Y and Beydoun MA (2007). The obesity epidemic in the United States - gender, age, socioeconomic, racial/ethnic, and geographic characteristics: a systematic review and meta-regression analysis. Epidemiol. Rev. 29: 6-28.

WHO (2000). Obesity: Preventing and Managing the Global Epidemic. Report of World Health Organization, Technical Report Series, No. 894.

WHO (2003). Diet, Nutrition and the Prevention of Chronic Diseases. (WHO) Technical Report Series, No. 916.

Wu YF, Ma GS, Hu YH, Li YP, et al. (2005). The current prevalence status of body overweight and obesity in China: data from the China National Nutrition and Health Survey. Zhonghua Yu Fang Yi Xue Za Zhi. 39: 316-320.

Zhang L, Shi K and Wu YZ (2010). Study on overweight, obesity and chronic diseases among residents in Chongqing city. Chin. Prev. Med. 11: 975-978. 